\title{
Viabilidade da fertirrigação por pivô central com uso de efluentes tratados em diferentes níveis
}

\author{
Job Teixeira de OLIVEIRA ${ }^{1 *}$, Priscila da Silva MARADINI², \\ Alisson Carraro BORGES ${ }^{2}$, Ricardo GAVA ${ }^{1}$
}

\author{
${ }^{1 *}$ Departamento de Agronomia, Universidade Federal do Mato Grosso do Sul, Chapadão do Sul, MS, Brasil. \\ ${ }^{2}$ Departamento de Engenharia Agrícola, Universidade Federal de Viçosa, Viçosa, MG, Brasil. \\ *E-mail: job.oliveira@hotmail.com \\ (ORCID: 0000-0001-9046-0382; 0000-0003-2352-2795; 0000-0002-9729-6439; 0000-0001-6268-5728)
}

Recebido em 29/07/2020; Aceito em 06/01/2021; Publicado em 10/02/2021.

\begin{abstract}
RESUMO: O objetivo deste trabalho foi verificar a viabilidade econômica do uso de esgotos sanitários, tratados com diferentes níveis de eficiência, para fertirrigação por pivô central em cultivos de algodão e soja. $\mathrm{O}$ estudo foi desenvolvido por meio da simulação e comparação de dois projetos de tratamento de esgoto sanitário a serem instalados na cidade de Correntina (BA). Para os cálculos de viabilidade, utilizou-se a planilha eletrônica AmazonSaf. Foram propostos dois cenários para o tratamento de esgoto para posterior fertirrigação: cenário A (pré-tratamento seguido de lagoa anaeróbia) e cenário B (pré-tratamento seguido de sistema australiano de lagoas e polimento com a ecotecnologia dos wetlands). Observou-se que os custos totais foram maiores no cenário $\mathrm{B}$, devido ao aumento no investimento com o tratamento via wetland. O aumento direto foi de $0,82 \%$, com um período de retorno do investimento de 8,7 anos. Há viabilidade econômica em reutilizar o efluente sanitário tratado do município de Correntina para irrigação de algodão e soja, independentemente do sistema de tratamento a ser adotado, embora a complementação do processo com a instalação do sistema de wetland se faça vantajosa do ponto de vista econômico, ambiental e social.
\end{abstract}

Palavras-chave: análise financeira; economia circular; fertirrigação; reuso; sustentabilidade.

\section{Feasibility of central pivot fertirrigation with the use of effluents treated at different levels}

\begin{abstract}
The objective of this work was to verify the economic viability of using sanitary sewage, treated with different levels of efficiency, for central pivot fertigation in cotton and soybean crops. The study was developed through the simulation and comparison of two sanitary sewage treatment projects to be installed in the city of Correntina (BA). For feasibility calculations, the AmazonSaf spreadsheet was used. Two scenarios were proposed for the treatment of sewage for subsequent fertigation: scenario A (pre-treatment followed by anaerobic lagoon) and scenario B (pre-treatment followed by Australian pond system and polishing with wetland ecotechnology). It was observed that the total costs were higher in scenario B, due to the increase in investment with wetland treatment. The direct increase was $0.82 \%$, with a payback period of 8.7 years. There is economic viability in reusing the treated sanitary effluent from the municipality of Correntina for irrigation of cotton and soy, regardless of the treatment system to be adopted, although complementing the process with the installation of the wetland system is advantageous from an economic point of view, environmental and social.

Keywords: financial analysis; circular economy; fertigation; reuse; sustainability.
\end{abstract}

\section{INTRODUÇÃO}

O saneamento básico é reconhecido como um direito humano pela Organização das Nações Unidas (ONU) e, no Brasil, é assegurado pela Lei Federal $n^{\circ} 11.445 / 2007$ (BRASIL, 2007).

Entre as ações que compõem os serviços de saneamento, o esgotamento sanitário merece destaque. Os números de saneamento no Brasil mostram que $43 \%$ da população possui esgoto coletado e tratado e $12 \%$ utilizam-se de soluções individuais (esgotamento descentralizado), ou seja, 55\% possuem tratamento considerado adequado. Por outro lado, $18 \%$ têm seu esgoto coletado e não tratado, o que pode ser considerado como um atendimento precário; e $27 \%$ não possuem coleta nem tratamento, isto é, não têm acesso ao serviço de saneamento básico, sendo a maioria residente em zonas rurais (ANA, 2017).
Desse modo, estudos voltados para o desenvolvimento e otimização de sistemas de tratamento de esgoto têm sido realizados e os wetlands (Sistemas Alagados Construídos SACs) estão entre as tecnologias atuais mais eficazes e empregadas principalmente em zonas rurais, devido ao fácil acesso, aparência natural e baixo custo de construção, manutenção e operação (LISTOSZ et al., 2018). Entretanto, tais sistemas necessitam de tratamento preliminar para aumentar a eficiência e evitar a colmatação (MATOS; MATOS, 2017). Assim, é necessário o tratamento prévio dos esgotos, de maneira que os sólidos suspensos e outros poluentes sejam removidos. Geralmente os wetlands (principalmente os de escoamento sub-superficial) são precedidos de reatores anaeróbios ou sistemas de lagoas (MELO; LINDNER, 2013).

Após o tratamento do esgoto sanitário é comum o 
lançamento do efluente tratado nos cursos d'água, e nem sempre são respeitadas as condições e padrões exigidos pela Resolução CONAMA n 430/2011 (BRASIL, 2011). Alguns compostos, como nitrogênio, fósforo e patógenos, são mais difíceis de serem removidos pelo tratamento em nível secundário nas estações de tratamento de esgotos e, quando lançados em excesso no meio podem ocasionar sérios problemas ambientais, como a eutrofização (MENDONÇA et al., 2012; GERHARDT et al., 2018). Além disso, tais elementos são considerados nutrientes limitantes para o crescimento e produtividade de cultivos agrícolas.

Desse modo, a fim de alcançar uma produção mais sustentável tem-se buscado alternativas como a aplicação de águas residuárias no solo. Uma das propostas atualmente empregada é a fertirrigação, que garante a manutenção da qualidade do solo e a minimização do risco de contaminação de águas superficiais e subterrâneas (MATOS; MATOS, 2017). As lâminas aplicadas neste tipo de sistema são determinadas pela demanda nutricional da cultura a ser fertirrigada (situação mais comum) ou pela necessidade hídrica das plantas (situação análoga à irrigação convencional, ocorrente quando a água de reuso possui excelente qualidade).

O pivô central se enquadra como um dos sistemas de irrigação mais utilizados para cultivos no Brasil devido a sua eficiência de aplicação, pequeno consumo de energia por unidade de área, pouca exigência de mão-de-obra, possibilidade de automação e facilidade de operação. Tratase de um sistema motomecanizado, caracterizado por irrigar grandes áreas, requerer pouca mão de obra, apresentar facilidade em automação e quimigação, oferecer boa uniformidade de aplicação e facilitar a sucessão de culturas por não precisar ser removido para plantio, tratos culturais, nem colheita (SANDRI; CORTEZ, 2009; CARVALHO; OLIVEIRA, 2012).

Na Bahia, em 2018, o algodão foi considerado uma referência histórica na qualidade, produção e comercialização da commodity. A região oeste, que concentra $96 \%$ da atividade no Estado, colhe 1,2 milhão em toneladas de algodão em caroço, com um rendimento de fibra acima de $42 \%$, que somaram mais de 500 milhões de toneladas e 0,5 milhão em toneladas de plumas (AIBA, 2019).

A soja ocupa mais de $65 \%$ da área total cultivada na região do Oeste da Bahia correspondendo a $5 \%$ da produção nacional e a 58\% da produção do Nordeste. A safra 2017/18 registrou um recorde histórico ao contabilizar uma a produção de cerca 5,3 milhões de toneladas da oleaginosa, um incremento da ordem de $15 \%$ em relação à anterior. Este resultado foi obtido graças ao aumento da produtividade, batendo o recorde de 66 sacas por hectares (AIBA, 2019).

Com base no exposto, neste trabalho objetivou-se verificar a viabilidade econômica do aproveitamento de esgoto sanitário do município de Correntina, na região oeste do estado da Bahia, para fertirrigação via pivô central, em cultivos de algodão e soja. No estudo comparou-se os efluentes advindos de duas diferentes tipologias de tratamento: tratamento primário (cenário A) e tratamento terciário, com uso da ecotecnologia wetland (cenário B).

\section{MATERIAL E MÉTODOS}

O estudo para análise de viabilidade econômica foi desenvolvido por meio da simulação e comparação de dois projetos de tratamento de esgoto da cidade de Correntina (BA) a saber:
Cenário A: Projeto composto por uma estação de tratamento de esgoto (ETE) com pré-tratamento convencional (gradeamento e desarenação) seguido de lagoa anaeróbia. A literatura é divergente em relação à classificação deste tipo de tratamento: em relação às eficiências, tem-se níveis modestos, classificando-a como tratamento primário. Contudo, devido à existência de mecanismos biológicos na lagoa, também se aceita que a lagoa anaeróbia é um tipo de tratamento secundário. Por segurança, considerou-se neste trabalho que o cenário A seja "tratamento primário".

Cenário B: Projeto composto por uma estação de tratamento de esgoto (ETE) com pré-tratamento, seguido de um sistema australiano de lagoas (unidade anaeróbia seguida de unidade facultativa fotossintética) e polido em um wetland.

Os custos de rede de esgoto foram calculados em função da projeção de habitantes da cidade, estimado para o ano de 2038 em 34.000 habitantes. De acordo com a Nota Técnica SNSA n ${ }^{\circ} 492 / 2010$, o custo médio de instalação para a rede de esgoto na região Nordeste é de $\mathrm{R} \$ \quad 67,00 \mathrm{hab}^{-1}$, considerando um índice de 3,3 habitantes por domicílio (SNSA, 2011). Os custos referentes às estações de tratamento foram obtidos conforme Von Sperling (2007).

Tanto o efluente do tratado do cenário A quanto o do cenário B seriam direcionados ao uso agrícola (fertirrigação de culturas de algodão e soja) via pivôs centrais.

Os projetos de pivôs centrais foram dimensionados com a mesma lâmina de irrigação, equivalente à $8,0 \mathrm{~mm} \mathrm{~d}^{-1}$, e para funcionamento $21 \mathrm{~h} \mathrm{~d}^{-1}$. Os pivôs são de aço zincado e altura de equipamento de 2,7 metros de vão livre. Além disso, são constituídos de três equipamentos completos, sendo P1 e P2 com 80 ha cada um e P3 com 107 ha.

Os cálculos foram feitos utilizando o programa MOD16, calibrado para obtenção da taxa de Evapotranspiração de Referência (ETo) mensal na área em estudo. Calculou-se a ETo variando entre 47 e $198 \mathrm{~mm}$. Na região oeste da Bahia, nos meses de outubro a março ocorrem os maiores valores de evapotranspiração e entre os meses de abril a setembro, os menores valores. A lâmina de projeto foi calculada utilizando um coeficiente de cultura máximo ( $\left.\mathrm{Kc}_{\mathrm{máx}}\right)$ de 1,05 correspondente ao período de maior demanda das culturas do algodão e da soja (ALLEN et al., 1998). Adotou-se uma eficiência de aplicação de $85 \%$ para pivô central (BERNARDO et al., 2019).

Para o cálculo da lâmina adotada no manejo de irrigação entre os meses de abril a outubro (período de estiagem), utilizou-se o $\mathrm{Kc}_{\text {máx }}$. Consideraram-se 180 dias de irrigação por ano, sendo 25 dias de irrigação em cultivo de primavera/verão (soja), 25 dias de irrigação em cultivo de verão/outono (algodão) e 130 dias de irrigação para a cultura de inverno/primavera (algodão), com ciclo médio de 120 dias para a soja e 180 dias para algodão. Foram consideradas 2 safras por ano, com cerca de 300 dias de ocupação da terra.

Após o dimensionamento hidráulico dos projetos de pivôs centrais com área total de 267 ha e com desnível de terreno de 3,0 \%, analisaram-se as viabilidades técnicoeconômicas. Os orçamentos dos projetos de irrigação dimensionados e o valor das infraestruturas de energia e transformadores de energia foram obtidos em estabelecimentos comerciais especializados na área de irrigação. O levantamento de dados necessários para implantação das culturas foi obtido no livro de referência nacional de custos de produção (AGRIANUAL, 2019).

Para os cálculos de viabilidade, utilizou-se a planilha eletrônica AmazonSaf (ARCO-VERDE; AMARO, 2014). A 
viabilidade do investimento foi avaliada pelo indicador de lucratividade, pelo valor presente líquido e pelo valor presente dos custos (FRIZZONE; ANDRADE JÚNIOR, 2005). Os indicadores utilizados na avaliação da viabilidade do investimento foram a receita bruta (Equação 1), o valor presente líquido (Equação 2), a taxa interna de retorno (Equação 3) e a relação benefício/custo (Equação 4).

$$
\begin{aligned}
& R B=P d x P V \\
& V P L=\sum_{j-0}^{n} \frac{C F_{j}}{(1+i)^{j}} \\
& T I R=\sum_{j-0}^{n} \frac{C F_{j}}{(1+i)^{j}}=0 \\
& \frac{B}{C}=\frac{\sum_{k-0}^{n} B_{k}(1+j)^{-k}}{\sum_{k-0}^{n} C_{k}(1+j)^{-k}}
\end{aligned}
$$

em que, RB - receita bruta, R\$; Pd - produção na área de estudo, kg; $\mathrm{PV}$ - preço de venda, $\mathrm{R} \$ \mathrm{~kg}^{-1}$; VPL - valor presente líquido, $\mathrm{R} \$ \mathrm{CF}$ - saldo do fluxo de caixa, R $\$ ;$ i - taxa de juros, $\% ; j$ - taxa de juros anual, \%; TIR - taxa interna de retorno, \%; B - benefício, R\$; C custo, $\mathrm{R} \$ \mathrm{~K}$ - vida útil, anos.

O valor presente líquido (VPL) é definido como a diferença entre o valor presente dos benefícios e o valor presente dos custos (FRIZZONE; ANDRADE JÚNIOR, 2005).

A taxa interna de retorno consiste no potencial do projeto de gerar retornos. Quando aplicada ao cálculo do VPL, essa taxa zera o resultado (GARZEL, 2003; FRIZZONE; ANDRADE JUNIOR, 2005).

Para os cálculos, foi utilizada uma taxa mínima de atratividade (TMA), equivalente a 4\%. A diferença entre a TIR e a TMA é o prêmio esperado pelo investidor com a implantação do projeto. O período de recuperação é o tempo que o projeto leva para retornar o capital investido (NORONHA, 1987). O parâmetro benefício/custo (B/C) é a razão por meio da qual é verificado se os benefícios são maiores que os custos (FRIZZONE; ANDRADE JÚNIOR, 2005).

A produtividade das culturas em cada safra de algodão e soja foram 300,0@ e 53,3 sacas respectivamente, analisando 40 colheitas em 20 anos. Os preços de venda da soja foram considerados no valor de $\mathrm{R} \$ 60,00 \mathrm{sc}^{-1}$ e do algodão no valor de R\$60,00@-1. Os valores de produtividade considerados são aceitos e utilizados pela associação de agricultores e irrigantes da Bahia em projeções e financiamentos. As receitas elaboradas para os fluxos de caixa resultaram das projeções da produtividade, áreas e preços.

\section{RESULTADOS}

Os resultados revelaram que os custos totais de produção das culturas utilizando irrigação por pivô central que foram $\mathrm{R} \$ 11.134,00 \mathrm{ha}^{-1}$ e $\mathrm{R} \$ 11.225,00 \mathrm{ha}^{-1}$, respectivamente para os cenários A e B (Tabelas 1 e 2).

Tabela 1. Porcentagem de investimentos e custo total de produção de algodão e soja irrigados por pivô central com efluente tratado do

\begin{tabular}{|c|c|c|c|c|}
\hline \multirow{2}{*}{ Investimentos/atividades/insumos } & \multicolumn{2}{|c|}{ Soja } & \multicolumn{2}{|c|}{ Algodão } \\
\hline & $\mathrm{R} \$ \mathrm{ha}^{-1}$ & $\%$ & $\mathrm{R} \$ \mathrm{ha}^{-1}$ & $\%$ \\
\hline Custo oportunidade do capital & 45,30 & 1,6 & 223,79 & 2,7 \\
\hline Depreciação & 570,01 & 19,8 & 570,01 & 6,9 \\
\hline Energia elétrica & 235,96 & 8,2 & 353,93 & 4,3 \\
\hline Manutenção & 16,18 & 0,6 & 24,27 & 0,3 \\
\hline Custos administrativos & 6,81 & 0,2 & 6,81 & 0,1 \\
\hline Impostos com Funrural & 70,37 & 2,4 & 395,51 & 4,8 \\
\hline Preparo e plantio e tratos & $1.335,70$ & 46,4 & $5.979,00$ & 72,4 \\
\hline Outras despesas & 500,00 & 17,4 & 500,00 & 6,1 \\
\hline Colheita & 100,00 & 3,5 & 200,00 & 2,4 \\
\hline Totais pivô + ETE primária & $2.880,32$ & 100 & $8.253,31$ & 100 \\
\hline
\end{tabular}
município de Correntina (BA) - Cenário A.

Table 1. Percentage of investments and total cost of cotton and soy production irrigated by central pivot with treated effluent from the municipality of Correntina (BA) - Scenario A.

Tabela 2. Porcentagem de investimentos e custo total de produção de algodão e soja irrigados por pivô central com efluente tratado do

\begin{tabular}{|c|c|c|c|c|}
\hline \multirow{2}{*}{ Investimentos/atividades/insumos } & \multicolumn{2}{|c|}{ Soja } & \multicolumn{2}{|c|}{ Algodão } \\
\hline & $\mathrm{R} \$ \mathrm{ha}^{-1}$ & $\%$ & $\mathrm{R} \$ \mathrm{ha}^{-1}$ & $\%$ \\
\hline Custo oportunidade do capital & 45,30 & 1,5 & 223,79 & 2,7 \\
\hline Depreciação & 615,56 & 21,0 & 615,56 & 7,4 \\
\hline Energia elétrica & 235,96 & 8,1 & 353,93 & 4,3 \\
\hline Manutenção & 16,18 & 0,6 & 24,27 & 0,3 \\
\hline Custos administrativos & 6,81 & 0,2 & 6,81 & 0,1 \\
\hline Impostos com Funrural & 70,37 & 2,4 & 395,51 & 4,8 \\
\hline Preparo e plantio e tratos & $1.335,70$ & 45,7 & $5.979,00$ & 72,0 \\
\hline Outras despesas & 500,00 & 17,1 & 500,00 & 6,0 \\
\hline Colheita & 100,00 & 3,4 & 200,00 & 2,4 \\
\hline Totais pivô + ETE terciária & $2.925,87$ & 100 & $8.298,86$ & 100 \\
\hline
\end{tabular}
município de Correntina (BA) - Cenário B.

Table 2. Percentage of investments and total cost of cotton and soy production irrigated by central pivot with treated effluent from the municipality of Correntina (BA) - Scenario B.

$\mathrm{Na}$ composição total de valor de investimento, foram considerados valores de $\mathrm{R} \$ 15.000,00$ para construção das bases dos pivôs, $\mathrm{R} \$ 50.000,00$ para a construção da casa de bombas e R \$ 15.000,00 para abertura e fechamento da valeta 
para colocação da adutora e cabos de energia, e mais $\mathrm{R} \$$ 200.000,00 para infraestrutura elétrica composta de $1 \mathrm{~km}$ de rede de energia e transformador. $\mathrm{O}$ valor dos equipamentos de pivôs centrais P1, P2 e P3 foram, respectivamente, de R\$ 653.000,00; $\mathrm{R} \$ 594.000,00$ e $\mathrm{R} \$ 708.000,00$. O valor total dos projetos de pivôs centrais completos com todas as infraestruturas foi de $\mathrm{R} \$ 2.235 .000,00$.

Considerou-se o valor médio de $\mathrm{R} \$ 0,25$ por quilowatthora para energia. Para os custos de produção e coeficientes técnicos das culturas avaliadas, foram consideradas as planilhas divulgas pela AGRIANUAL, (2019).

Nas Tabelas 1 e 2, observa-se que, em média, 46,05\% e $72,2 \%$ do custo total de produção do sistema agrícola de soja e algodão, respectivamente, destinam-se a preparo, plantio, tratos culturais e colheita, considerando a média dos dois cenários. Os demais custos estão relacionados à irrigação e tratamento de esgoto (investimento com equipamentos hidráulicos dos tratamentos de esgoto e pivô, infraestrutura, energia, depreciação e manutenção).
Os limites de custos das ETEs para os cenários A e B estão apresentados na Tabela 3 . O valor gasto (implantação) no pré-tratamento seguido de lagoa anaeróbia foi de $\mathrm{R} \$$ 1.810.500,00. O tratamento completo, incluindo a lagoa facultativa (secundário) e wetland (terciário), por sua vez, teve o custo de $\mathrm{R} \$ 5.440 .000,00$. A rede de esgoto da cidade em estudo ficou em $\mathrm{R} \$ 2.278 .000,00$.

O custo de implantação do sistema completo de irrigação por pivô central, nos diferentes cenários (ETE e ETE + wetland), foi de $\mathrm{R} \$ 79.801,00 \mathrm{ha}^{-1}$ e $\mathrm{R} \$$ 86.179,00 ha-1, respectivamente. Observou-se aumento de $8 \%$ no custo de implantação do equipamento com reuso do efluente do sistema ETE + wetland comparado com o sistema ETE. Isto ocorreu devido ao aumento no investimento do projeto $(\mathrm{R} \$$ 21.306.920,00 para $\mathrm{R} \$ 23.009 .770,00)$.

As Tabelas 4 e 5 apresentam o lucro líquido acumulado, ao longo de 20 anos, com o equipamento de pivô central utilizando o efluente tratado provenientes dos dois cenários, respectivamente.

Tabela 3. Limites de custos de implantação das ETEs nos cenários A e B.

Table 3. Limits of costs for the implementation of WWTPs in scenarios A and B.

\begin{tabular}{|c|c|c|c|c|}
\hline & $\begin{array}{l}\text { Faixa de Custo de } \\
\text { Implantação }\left(\mathrm{R} \$ \text { hab-1 }^{-1}\right)\end{array}$ & $\begin{array}{l}\text { Custo de Implantação } \\
\text { Adotado }\left(\mathrm{R} \$ \text { hab }^{-1}\right)\end{array}$ & $\begin{array}{c}\text { Faixa de Custo de Operação e } \\
\text { Manutenção }\left(\mathrm{R} \$ \text { hab }^{-1}\right)\end{array}$ & $\begin{array}{c}\text { Custo de Operação e Manutenção } \\
\text { Previsto }\left(\mathrm{R} \$ \mathrm{hab}^{-1}\right)\end{array}$ \\
\hline $\mathrm{A}$ & $15,00-75,00$ & 50,00 & $2,50-4,00$ & 3,25 \\
\hline B & $100,00-200,00$ & 150,00 & $7,50-12,50$ & 10,00 \\
\hline
\end{tabular}

Fonte: Adaptado de Von Sperling (2007).

Tabela 4. Indicadores econômicos em vinte anos de investimento em um sistema de irrigação por pivô central em culturas de algodão e soja com efluente tratado do município de Correntina (BA) - Cenário A.

Table 4. Economic indicators in twenty years of investment in a central pivot irrigation system in cotton and soy crops with treated effluent from the municipality of Correntina (BA) - Scenario A.

\begin{tabular}{|c|c|c|c|c|}
\hline \multirow[b]{2}{*}{ Atividade } & \multicolumn{3}{|c|}{ Lucro } & \multirow[b]{2}{*}{ Avaliação financeira } \\
\hline & $\begin{array}{r}\text { Liquido } \\
\mathrm{R} \$ \mathrm{ha}^{-1} \\
\end{array}$ & $\begin{array}{c}\text { Operacional } \\
\mathrm{R} \$ \mathrm{ha}^{-1}\end{array}$ & $\begin{array}{l}\text { Acumulado } \\
\mathrm{R} \$ \mathrm{ha}^{-1}\end{array}$ & \\
\hline Ano 1 & $2.681 .321,36$ & $2.753 .167,53$ & $-18.623,29$ & \\
\hline Ano 2 & $2.681 .321,36$ & $2.753 .167,53$ & $-15.941,57$ & \\
\hline Ano 3 & $2.681 .321,36$ & $2.753 .167,53$ & $-13.259,86$ & \\
\hline Ano 4 & $2.681 .321,36$ & $2.753 .167,53$ & $-10.578,15$ & \\
\hline Ano 5 & $2.681 .321,36$ & $2.753 .167,53$ & $-7.896,44$ & \\
\hline Ano 6 & $2.681 .321,36$ & $2.753 .167,53$ & $-5.214,72$ & \\
\hline Ano 7 & $2.681 .321,36$ & $2.753 .167,53$ & $-2.533,01$ & Payback \\
\hline Ano 8 & $2.681 .321,36$ & $2.753 .167,53$ & 148,70 & 7 anos \\
\hline Ano 9 & $2.681 .321,36$ & $2.753 .167,53$ & $2.830,42$ & 11 meses \\
\hline Ano 10 & $2.681 .321,36$ & $2.753 .167,53$ & $5.512,13$ & \\
\hline Ano 11 & $2.681 .321,36$ & $2.753 .167,53$ & $8.193,84$ & \\
\hline Ano 12 & $2.681 .321,36$ & $2.753 .167,53$ & $10.875,56$ & \\
\hline Ano 13 & $2.681 .321,36$ & $2.753 .167,53$ & $13.557,27$ & \\
\hline Ano 14 & $2.681 .321,36$ & $2.753 .167,53$ & $16.238,98$ & \\
\hline Ano 15 & $2.681 .321,36$ & $2.753 .167,53$ & $18.920,70$ & \\
\hline Ano 16 & $2.681 .321,36$ & $2.753 .167,53$ & $21.602,41$ & \\
\hline Ano 17 & $2.681 .321,36$ & $2.753 .167,53$ & $24.284,12$ & \\
\hline Ano 18 & $2.681 .321,36$ & $2.753 .167,53$ & $26.965,83$ & \\
\hline Ano 19 & $2.681 .321,36$ & $2.753 .167,53$ & $29.647,55$ & \\
\hline Ano 20 & $2.681 .321,36$ & $2.753 .167,53$ & $32.329,26$ & \\
\hline
\end{tabular}

Os resultados mostram que mesmo com uma variação no valor de investimento nos equipamentos de pivôs com uso da água proveniente do sistema ETE + wetland (Cenário A), o aumento direto foi de $0,82 \%$ na média dos custos totais de produção (Tabelas 1 e 2). Tal fato revela a viabilidade da instalação do empreendimento do cenário B (Tabela 6), com rentabilidade (VPL) de $\mathrm{R} \$ 27.989,00 \mathrm{ha}^{-1} \mathrm{ano}^{-1}$ da média total de VPL de R \$31.699,00 ha- $\mathrm{ano}^{-1}$.

Para os dois cenários avaliados (Tabela 6), verificou-se que a razão benefício/custo (lucro) foi maior do que 1,0, pois o valor médio de $\mathrm{B} / \mathrm{C}$ foi igual a $\mathrm{R} \$ 1,12$ para a soja e 2,24 para o algodão. $\mathrm{O}$ resultado acumulativo permitiu calcular o período de retorno do capital investido (período de amortização do investimento) em sete anos e onze meses para o uso do pivô central com o efluente tratado em nível primário (Tabela 4) e oito anos e oito meses para o uso do pivô com o efluente tratado em nível avançado, com uso de wetland (Tabela 5). 
Além disso, a taxa interna de retorno (TIR) média obtida foi de $11,93 \%$ e $123,26 \%$ para soja e algodão, respectivamente. $\mathrm{Na}$ região do estudo, essas duas culturas são as mais cultivadas, e desse modo, para um período de 20 anos, o produtor conseguiria abater os custos de implantação dos pivôs para fertirrigação das duas culturas. Vale destacar que um equipamento de pivô central tem longevidade superior a 30 anos desde que bem manejado e com todas as revisões feitas corretamente.

Tabela 5. Indicadores econômicos em vinte anos de investimento em um sistema de irrigação por pivô central em culturas de algodão e soja com efluente tratado do município de Correntina (BA) - Cenário B.

Table 5. Economic indicators in twenty years of investment in a central pivot irrigation system in cotton and soy crops with treated effluent from the municipality of Correntina (BA) - Scenario B.

\begin{tabular}{|c|c|c|c|c|}
\hline \multirow{2}{*}{ Atividade } & \multicolumn{3}{|c|}{ Lucro $\left(\mathrm{R} \$\right.$ ha $\left.^{-1}\right)$} & \multirow{2}{*}{ Avaliação financeira } \\
\hline & Liquido & Operacional & Acumulado & \\
\hline Ano 1 & $2.656 .994,93$ & $2.728 .840,80$ & $-20.349,61$ & \\
\hline Ano 2 & $2.656 .994,93$ & $2.728 .840,80$ & $-17.692,21$ & \\
\hline Ano 3 & $2.656 .994,93$ & $2.728 .840,80$ & $-15.034,82$ & \\
\hline Ano 4 & $2.656 .994,93$ & $2.728 .840,80$ & $-12.377,42$ & \\
\hline Ano 5 & $2.656 .994,93$ & $2.728 .840,80$ & $-9.720,03$ & \\
\hline Ano 6 & $2.656 .994,93$ & $2.728 .840,80$ & $-7.062,63$ & \\
\hline Ano 7 & $2.656 .994,93$ & $2.728 .840,80$ & $-4.405,24$ & \\
\hline Ano 8 & $2.656 .994,93$ & $2.728 .840,80$ & $-1.747,84$ & Payback. \\
\hline Ano 9 & $2.656 .994,93$ & $2.728 .840,80$ & 909,55 & 8 anos \\
\hline Ano 10 & $2.656 .994,93$ & $2.728 .840,80$ & $3.566,95$ & 8 meses \\
\hline Ano 11 & $2.656 .994,93$ & $2.728 .840,80$ & $6.224,34$ & \\
\hline Ano 12 & $2.656 .994,93$ & $2.728 .840,80$ & $8.881,74$ & \\
\hline Ano 13 & $2.656 .994,93$ & $2.728 .840,80$ & $11.539,13$ & \\
\hline Ano 14 & $2.656 .994,93$ & $2.728 .840,80$ & $14.196,53$ & \\
\hline Ano 15 & $2.656 .994,93$ & $2.728 .840,80$ & $16.853,92$ & \\
\hline Ano 16 & $2.656 .994,93$ & $2.728 .840,80$ & $19.511,32$ & \\
\hline Ano 17 & $2.656 .994,93$ & $2.728 .840,80$ & $22.168,71$ & \\
\hline Ano 18 & $2.656 .994,93$ & $2.728 .840,80$ & $24.826,11$ & \\
\hline Ano 19 & $2.656 .994,93$ & $2.728 .840,80$ & $27.483,50$ & \\
\hline Ano 20 & $2.656 .994,93$ & $2.728 .840,80$ & $30.140,90$ & \\
\hline
\end{tabular}

Tabela 6. Indicadores econômicos em vinte anos de investimento em sistemas de irrigação por pivô central em culturas de algodão e soja com efluente tratado do município de Correntina (BA) - comparação dos 2 cenários.

Table 6. Economic indicators in twenty years of investment in irrigation systems by central pivot in cotton and soy crops with treated effluent from the municipality of Correntina (BA) - comparison of the 2 scenarios.

\begin{tabular}{lccccccccc}
\hline \multirow{2}{*}{ Atividade Agrícola } & \multicolumn{2}{c}{ Rentabilidade } & \multicolumn{2}{c}{ Lucratividade } & \multicolumn{2}{c}{ Taxa de Retorno } & \multicolumn{2}{c}{ B/C } & \multirow{2}{*}{\begin{tabular}{c} 
Contribuição, \\
\cline { 2 - 8 } R $\$$ VPL ha $^{-1}$
\end{tabular}} \\
\cline { 2 - 8 } Pivô+ETE & Soja & Algodão & Soja & Algodão & Soja & Algodão & Soja & Algodão & $35.408,38$ \\
Pivô+ETE+Wetland & $11,05 \%$ & $117,82 \%$ & $9,95 \%$ & $54,09 \%$ & $12,82 \%$ & $123,89 \%$ & 1,13 & 2,24 & $27.989,18$ \\
\hline Média & $9,32 \%$ & $116,63 \%$ & $8,52 \%$ & $53,84 \%$ & $11,04 \%$ & $122,63 \%$ & 1,11 & 2,23 & $31.698,78$ \\
\hline
\end{tabular}

\section{DISCUSSÃO}

O custo de produção do algodão foi 2,85 vezes o da soja, em razão dos altos custos com preparo do solo, sementes e plantio que, juntos, representaram $72,2 \%$ dos custos, considerando a média dos dois cenários. Resultados encontrados por Pereira et al. (2015) foram de 55,6\% custos com insumos e mão-de-obra para implantação, condução e renovação dos canaviais em sistema de irrigação plena.

Além disso, como as culturas apresentam custos de produção distintos, os custos de oportunidade do capital investido (sistema de irrigação e infraestrutura para implantação da irrigação) foi dividido igualmente para soja e algodão, que representaram 1,5 e 2,7\% respectivamente dos custos totais de produção de cada cultura (Tabelas 1 e 2). Em trabalho desenvolvido por Pereira et al. (2015), essa participação devido à implantação do projeto de irrigação, representou aproximadamente $10 \%$ dos custos totais de cultivo da cana de açúcar nos manejos com irrigação plena.

A reutilização de efluente tratado para fertirrigação, ainda, apresenta benefícios como (i) economia em fertilizantes, pois estes estarão na forma solúvel podendo ser prontamente absorvido pelas raízes das culturas; (ii) controle da profundidade de aplicação, em função da lâmina de água; (iii) redução do consumo de água do rio do município (Rio Corrente), que já enfrenta conflitos de uso da água; (iv) menor compactação do solo e danos físicos às culturas; (v) menor custo com mão de obra e (vi) melhor índice de desenvolvimento humano (IDH) da cidade (PINTO, 2019).

A Lei ${ }^{\circ} 9.433 / 1997$ instituiu a Política Nacional de Recursos Hídricos e a cobrança do uso dos recursos hídricos (BRASIL, 1997). Desse modo, a reutilização do efluente tratado se torna ainda mais interessante, uma vez que possibilita a diminuição dos custos relacionados à outorga de direito de uso dos recursos hídricos no que tange o lançamento de efluentes, tratados ou não, nos corpos de água. Além disso, o aproveitamento de todo o efluente tratado corrobora com o uso consciente e sustentável da água.

Em relação aos aspectos sanitários e ambientais, o sistema de tratamento contemplado no cenário A, apresenta riscos sanitários principalmente para os operadores das culturas, uma vez que não ocorre remoção de patógenos. Em 
contrapartida, a remoção de nitrogênio é na faixa de 10 a $25 \%$, de modo a fornecer em torno de metade da adubação nitrogenada necessária para a cultura do algodão e $25 \%$ da adubação para a soja, sem maiores riscos de lixiviação de nitrato (VON SPERLING, 2007).

No cenário B, por sua vez, o sistema é mais completo, apresentando uma faixa de 3 a 5 unidades logarítmicas removidas de coliformes, ou seja, em torno de $10^{3} \mathrm{NMP} d \mathrm{~d}$ 1 presentes no efluente tratado (DOTRO et al., 2017; VON SPERLING, 2007). Desse modo, a complementação do tratamento primário com uma lagoa facultativa fotossintética seguida do sistema de wetland (tratamento terciário) se faz vantajosa do ponto de vista sanitário e ambiental, uma vez que melhora a qualidade do efluente tratado, com um maior rigor quanto à prevenção de riscos de lixiviação de nitratos concomitante à maior remoção de patógenos; e também do ponto de vista econômico, por conciliar custos reduzidos de implantação, operação e manutenção (MATOS; MATOS, 2017).

\section{CONCLUSÕES}

Há viabilidade econômica em reutilizar o efluente sanitário tratado do município de Correntina para irrigação de algodão e soja, independentemente do sistema de tratamento a ser adotado, embora a complementação do processo com a instalação do sistema de wetland tenha um investimento superior, apresentando taxa de retorno acima de $11 \%$ para a soja e $123 \%$ para o algodão.

\section{AGRADECIMENTOS}

Este estudo foi financiado em parte pela Coordenação de Aperfeiçoamento de Pessoal de Nível Superior - Brasil (CAPES) - Código Financeiro 001.

Este trabalho foi realizado com o apoio do $\mathrm{CNPq}$, Conselho Nacional de Desenvolvimento Científico e Tecnológico - Brasil. (Processo 141231/2019-0).

\section{REFERÊNCIAS}

ANA_Agência Nacional de Águas (Brasil). Atlas esgotos: despoluição de bacias hidrográficas. Agência Nacional de Águas, Secretaria Nacional de Saneamento Ambiental. Brasília: ANA, 2017. 88 p.

AGRIANUAL. Anuário da agricultura Brasileira. São Paulo: FNP: Consultoria Andamp; $24^{a}$ edição. Comércio: 2019. 497 p.

ALLEN, R. G. et al. Crop evapotranspiration: Guidelines for computing crop water requirements. Rome: FAO, 1998. (FAO - Irrigation and Drainage Paper, 56). 1998. $300 \mathrm{p}$.

ARCO-VERDE, M. F.; AMARO, G. Cálculo de indicadores financeiros para sistemas agroflorestais. 2 ed. Boa Vista: Embrapa Roraima, 2014. 36 p. (Documentos, 57).

AIBA_ASSOCIAÇÃO DE AGRICULTORES E IRRIGANTES DA BAHIA. Anuário da Região Oeste da Bahia: Safra 2010/12. Bahia, 2012. 32p. Disponível em: $\quad<\quad$ http://aiba.org.br/wpcontent/uploads/2013/11/

anuario_oeste_bahia_2012.pdf $>$. Acesso em 24/04/2020

BERNARDO, S.; SOARES, A. A.; MANTOVANI, E. C.
Manual de irrigação. 9 ed. Viçosa: UFV, 2019. 545 p. BRASIL. Lei $\mathbf{n}^{\circ} \mathbf{9 . 4 3 3}$ de 8 de janeiro de 1997. Institui a Política Nacional de Recursos Hídricos, cria o Sistema Nacional de Gerenciamento de Recursos Hídricos, regulamenta o inciso XIX do art. 21 da Constituição Federal, e altera o art. $1^{\circ}$ da Lei no 8.001 , de 13 de março de 1990, que modificou a Lei $n^{\circ} 7.990$, de 28 de dezembro de 1989. 1997. 13 p. Disponível em: https://saneamentobasico.com.br/wpcontent/uploads/2017/07/politica-nacional-derecursos-hidricos.pdf. Acesso em 02/02/2021.

BRASIL. Lei $\mathbf{n}^{\circ} \mathbf{1 1 . 4 4 5}$, de 5 de janeiro de 2007. Estabelece diretrizes nacionais para o saneamento básico. 2007. 20 p. Disponível https://www2.camara.leg.br/legin/fed/lei/2007/lei11445-5-janeiro-2007-549031-normaatualizada-pl.pdf. Acesso em 02/02/2021.

BRASIL. Resolução CONAMA n ${ }^{\circ} \mathbf{4 3 0}$ de 18 de maio de 2011. Dispõe sobre as condições e padrões de lançamento de efluentes, complementa e altera a Resolução no 357, de 17 de março de 2005, do Conselho Nacional do Meio Ambiente-CONAMA. 2011. 9 p. Disponível em: http://www2.mma.gov.br/port/conama/legiabre.cfm?c odlegi=646. Acesso em 02/02/2021.

CARVAlHO, D. F.; OLIVEIRA, L. F. C. Planejamento e manejo da água na agricultura irrigada. Viçosa: Editora UFV, v. 1, 2012. 240 p.

DOTRO, G.; LANGERGRABER, G.; MOLLE, P.; NIVALA, J.; PUIGAGUT, J.; STEIN, O.; VON SPERLING, M. Biological Wastewater Treatment Series: Treatment Wetlands. IWA Task Group on Mainstreaming the Use of Treatment Wetlands. Londres: IWA Publishing, 2017. 172 p.

FRIZZONE, J. A.; ANDRADE JÚNIOR, A. S. Planejamento de irrigação: análise de decisão de investimento. Brasília: Embrapa Informação Tecnológica, 2005. p. 626.

GERHARDT, R.; REISDORFER, G.; CARDOSO, M. G. Remoção de nitrogênio e fósforo de efluente industrial através da precipitação de estruvita. Tecno-Lógica, Santa Cruz do Sul, v. 22, n. 1, p. 35-40, 2018.

LISTOSZ, A.; KOWALCZYK-JUŚKO, A.; JÓŹWIAKOWSKI, K.; MARZEC, M.; URBAN, D.; TOKARZ, E.; LIGEZZA, S. Productivity and chemical properties of Salix viminalis in a horizontal subsurface flow constructed wetland during long-term operation. Ecological Engineering, v. 122, p. 76-83, 2018.

MATOS, A. T.; MATOS, M. P. Disposição de ÁguasResiduárias no Solo e em Sistemas Alagados Construídos. 1 ed. Viçosa, MG: Editora UFV, 2017. 371 p.

MELO, J. F.; LINDNER, E. A. Dimensionamento comparativo lagoas versus wetlands para o tratamento de esgoto em bairro de campos novos, SC. Unoesc \& Ciência, Joaçaba, v. 4, n. 2, p. 181-196, 2013.

MENDONÇA, H. V.; RIBEIRO, C. B. M.; BORGES, A. C.; BASTOS, R. R. Remoção de nitrogênio e fósforo de águas residuárias de laticínios por sistemas alagados construídos operando em bateladas. Ambiente e Ågua, Taubaté, v. 7, n. 2, p. 75-87, 2012.

NORONHA, J. F. Projetos agropecuários: administração financeira, orçamento e viabilidade econômica. 2 ed.

Nativa, Sinop, v. 9, n. 1, p. 23-29, jan./fev. 2021. 
São Paulo: Atlas, 1987. 269 p.

PEREIRA, R. M.; ALVES JUNIOR, J.; CASAROLI, D.; SALES, D. L.; RODRIGUES, W. D. M.; SOUZA, J. M. F.. Viabilidade econômica da irrigação de cana-de-açúcar no cerrado brasileiro. Irriga, Botucatu, Edição Especial. p. 149-157, 2015 DOI: https://doi.org/10.15809/irriga.2015v1n2p149

PINTO, J. M. Fertirrigação: como ela pode ajudar sua produção de cebola? Campo \& Negócios - Hortifruti. Embrapa Semiárido, 2019. 9 p.

SNSA. Nota técnica SNSA n²492/2010: Resumo 01/2011. Secretaria Nacional de Saneamento Ambiental. 2011. 20 p. Disponível em: https://antigo.mdr.gov.br/images/stories/ArquivosSN SA/Arquivos_PDF/Referencias_Custos_Globais_Siste mas_Saneamento_Basico.pdf. Acesso em 02/02/2021.

VON SPERLING, M. Biological wastewater treatment series. Volume 1: Wastewater characteristics, treatment and disposal. London: IWA Publishing, 2007. 296 p. 